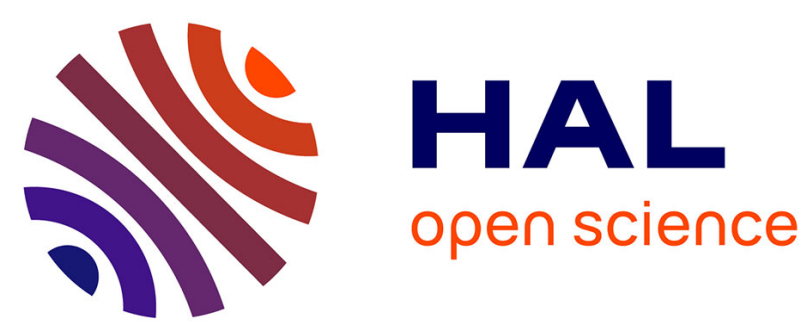

\title{
FAST LASER SPECTROSCOPY FOR DETERMINATION OF ENERGY TRANSFER ON THE FRACTAL STRUCTURE OF SILICA-GELS
}

Bernard Champagnon, J. Rousset, A. Monteil, M. Ferrari, E. Duval, A. Boukenter

\section{To cite this version:}

Bernard Champagnon, J. Rousset, A. Monteil, M. Ferrari, E. Duval, et al.. FAST LASER SPECTROSCOPY FOR DETERMINATION OF ENERGY TRANSFER ON THE FRACTAL STRUCTURE OF SILICA-GELS. Journal de Physique Colloques, 1987, 48 (C7), pp.C7-529-C7-531. 10.1051/jphyscol:19877126 . jpa-00226945

\section{HAL Id: jpa-00226945 https://hal.science/jpa-00226945}

Submitted on 1 Jan 1987

HAL is a multi-disciplinary open access archive for the deposit and dissemination of scientific research documents, whether they are published or not. The documents may come from teaching and research institutions in France or abroad, or from public or private research centers.
L'archive ouverte pluridisciplinaire HAL, est destinée au dépôt et à la diffusion de documents scientifiques de niveau recherche, publiés ou non, émanant des établissements d'enseignement et de recherche français ou étrangers, des laboratoires publics ou privés. 
FAST LASER SPECTROSCOPY FOR DETERMINATION OF ENERGY TRANSFER ON THE FRACTAL STRUCTURE OF SILICA-GELS

B. ChAMPAGNON, J.L. ROUSSET, A. MONTEIL, M. FERRARI, E. DUVAL and A. BOUKENTER

Laborato1re de Physico-Chimie des Matériaux Luminescents, CNRS-UA 442 et Celphyra, Université Lyon $I$, F-69622 Villeurbanne Cedex, France

I. INTRODUCTION:

Fractal behaviour of various materials has been explored in these last years/1/. Between them Silica gels are widely oonsidered because their high degree of porosity; they have been studied by S.A.X.S.121. Neutrons Scattering/3/, Brillouin Soattering/4/, Low Frequency Raman Scattering/5/.. The use of energy transfer between dyes has been proposed some years ago but the fitting of the curves to deduce the fractal dimension $D$ is not quite convincing if too many parameters are oonsidered.

Taking into account this objection it is important to correlate the results between the different techniques and to reduce as much as possible the number of parameters when the energy transfer is used to test the fractal aspect of materials.

\section{II . EXPERIMENTS :}

The energy transfer has been measured using Rhodamine $B$ as the donor(concentration $0.6 \quad 10^{-5} \mathrm{~m} / \mathrm{l}$ ) and Halachite green as trap. Due to the life time of the Rhodamine $B$ (several ns) these experiments implies the use of a short laser pulse $(350 \mathrm{ps})$ in order to avoid any deconvolution. This laser pulse is provided by a Y.A.G.:Nd ${ }^{3+}$ Microcontrol laser in a laboratory of the CEIPHYRA in Grenoble (Laboratoire de Spectrometrie Physique). The frequency is doubled at $532 \mathrm{~nm}$ to excite the emission of Rhodamine $B$; the delay between two pulses is 10 nanosecondes during which the decay is recorded using a time to amplitude converter. The silica gels studied are of three densities and provided by the "Laboratoire de Soiences des Materiaux Vitreux" $(d=0.107, d=0.33)$ or by "Airglass" Sweden $(d=0.09)$. They are referred respectively as samples $a, b$ and $c$. They are prepared in basic medium with T.M.O.S and dried under hypercritical conditions (Aerogels).

\section{RESULTS AND DISCUSSION.}

The analysis of the luminescence decay is made using the description of KLAFTER and BLUMEN/6/:

$$
I(t)=I_{0} \operatorname{Exp}\left(-t / \tau-P(t / \tau)^{D / 8}\right)
$$

where $\tau$ is the life time of the donor, $s=6$ for a dipole-dipole interaction. The term $\mathrm{P}$ depends on factors 171 whioh oannot be properly evaluated but it has to be proportionnal to the concentration of the acceptors. We then use different values of the concentration of the acceptor and evaluate $P$ from the fitting of the curves. 
The life time $\tau$ is determined experimentally from the decay of Rhodamine $B$ in two of the considered Aerogels as its value varies from one to another. The fractal dimension $D$ is found by a non-linear regression by the Poreli's method.The value

$D=3$ corresponds to the normal space, $D$ different from 3 reveal a fractal behaviour.

The experimental results are shown on the figure 1 for the sample (a). The fraotal dimension is $D=2.1 \pm 0.3$ and the values of $P$ are in quite good agreement with the ratio of the concentrations of the acceptor. On the other hand the more dense sample (b) corresponds to $D=3$ (figure 2) which means that it has a non fractal behaviour.

This behaviour is defined according to the charaoteristic length explored by the energy transfer between the dyes considered.This result can be correlated with recent Small Angle Neutron Soattering experiments/3/ which showed that the correlation length $\xi$ corresponding to a fractal behaviour of Aerogels vary from approximately 300 A to 20 A when the density goes from 0.1 to 0.35 .
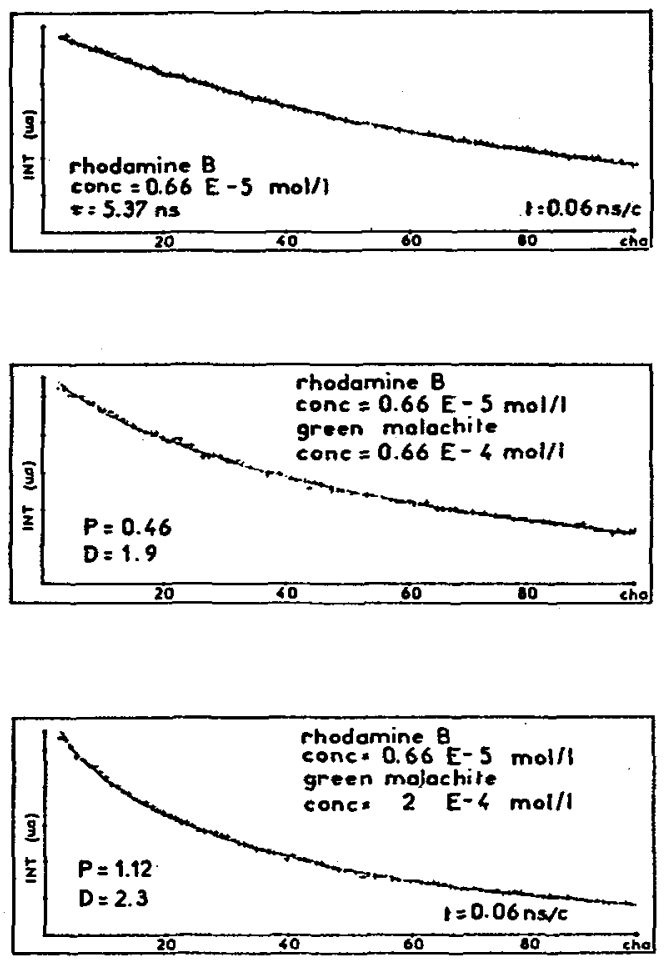

Fig 1:Decay of Rhodamine $B$ in Aerogel (a), $d=0.107$, without malaohite green and for differents concentrations. (+ corresponds to the experimental points, and the solid line to caloulated curve with indicated values of $D, P$ and $\tau$.

This point is in agreement also with the fractal behaviour vith $\mathrm{D}=2.3 \pm 0.3$ obtained for the lightest sample (c). This Aerogel is similar to the one studied by SHAEFER and KEEEER /3/ by S.A.X.S. where a slope of -2 is obtained in the Porod regime.

Fig 2:Decay of Rhodamine B in Aerogel (b), $d=0,33$, with malaohite green.

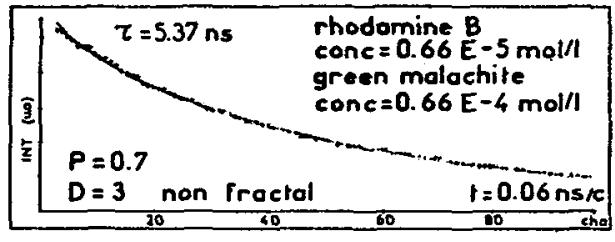




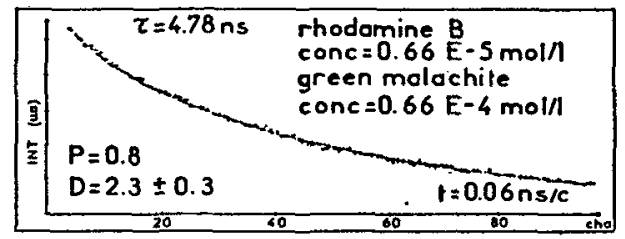

In sumary, the energy transfer between dyes shows its ability to test the fractality of Silica gels and gives good correlations with other types of experiments. Further works on Silica gels of different densities and use of dyes with different interaction lengths are planned.We are grateful to D.BLOCK and R.ROMESTAIN for their assistance in the experimental part of the work and to Rene CURNI from IUT 2 of Grenoble who wrote the fitting programm.

\section{REFERENCES :}

111 "Fractal aspects of materials" Symposium of the materials research society, BOSTON, 2-5 dec 1986.

12/D.W.SHAEFER and K.D.KEEFER Phys.Rev.letters 56, 2199, (1986).

/3/R. VACHER, T.WOIGNIER, J.PELOUS and E.COURTENS to be published.

14/E.COURTENS, J.PELOUS, R.VACHER and T WOIGNIER Phys.Rev.letters

$58,128,(1987)$.

15/A. BOUKENTER, B.CHAMPAGNON, E.DUVAL, J.DUMAS, J.F.OUINSON and

J.SERUGHETTI Phys.Rev. letters 57, 2391, (1986).

$16 / \mathrm{J}$.KLAETER and A.BLUYEN J.Chem. Phys. 80, 875, (1984).

17/U.EVEN, K.RADEMANN, J.JORTNER, N.MANOR and R.REISFELD Phys.Rev.

letters $52,2164,(1984)$.
Fig 3: Decay of Rhodamine $B$ in Aerogel (c), $d=0.09$, with green malachite. 